\title{
El excedente económico en Argentina: la etapa neoliberal (1991-2001) versus la neodesarrollista (2002-2015)
}

\author{
The Economic Surplus in Argentina: The \\ Neoliberal Stage (1991-2001) Versus Neo- \\ Developmental Stage (2002-2015)
}

\section{$O$ excedente econômico na Argentina: o estágio neoliberal (1991-2001) versus o neodesenvolvimentista (2002-2015)}

Leandro Marcelo Bona*

DOI: https://doi.org/10.19053/01203053.v37.n66.2019.6126

Fecha de recepción: 17 de mayo de 2017

Fecha de aprobación: 26 de enero de 2018

Cómo citar este artículo/ To reference this article / Comment citer cet article / Para citar este artigo:

Bona, L. (2018). El excedente económico en Argentina: la etapa neoliberal (1991-2001) versus la neodesarrollista (2002-2015). APUNTES DEL CENES, 37(66). https://doi.org/10.19053/01203053.v37.n66.2019.6126

* Licenciado en Economía (UNLP), Mg. en Economía Política (FLACSO). Doctorando en Desarrollo Económico (UNQ). Becario doctoral CONICET. Área de Economía y Tecnología de FLACSO, Buenos Aires, Argentina. leandrombona@gmail.com. (B) 0000-0002-0920-9754 


\section{Resumen}

Este trabajo se propone estudiar la evolución de la economía política argentina comparando los períodos de convertibilidad (1991-2001) y postconvertibilidad (2002-2015), recuperando el análisis que brinda la teoría del excedente económico (en sus versiones estructuralista y marxista). Para ello se definen y construyen series estadísticas de las variables necesarias para este propósito: el costo de reproducción social y el excedente económico, discriminando en este último caso sus usos productivos (inversión y ahorro) e improductivos (fuga de capitales y consumos suntuarios). La elaboración de estas series se realiza en base a diversos métodos de relevamiento y estimación que provienen de las Cuentas Nacionales, Internacionales y otras fuentes de información. Los resultados obtenidos indican 1) que el excedente económico representa más de la mitad del producto bruto interno, 2) que en la etapa neoliberal se observó un deterioro de las condiciones de reproducción social, mientras que sobre el segundo período de la etapa neodesarrollista esa tendencia se revirtió y 3) que los destinos del excedente económico en Argentina son mayormente improductivos y ello conspira contra las posibilidades de desarrollar una economía socialmente más equitativa y potencialmente más diversificada.

Palabras clave: Argentina, excedente económico, distribución del ingreso, neoliberalismo, neodesarrollismo.

Clasificación JEL: B50, E20, O10, O54, P16. 


\begin{abstract}
This paper aims to study the evolution of Argentina's political economy by comparing the periods of convertibility (1991-2001) and postconvertibility (2002-2015), recovering the analysis provided by the theory of economic surplus (in its Structuralist and Marxist versions). For this purpose, statistical series of the variables necessary for this purpose are defined and constructed: the cost of social reproduction and the economic surplus, discriminating in the latter case their productive uses (investment and savings) and unproductive uses (capital flight and luxury consumption). The preparation of these series is based on various methods of survey and estimation that come from the National Accounts, International Accounts and other sources of information. The results obtained indicate: 1) that economic surplus represents more than half of GDP, 2) that we observe a deterioration in the conditions of social reproduction in the neoliberal stage, while over the second period of the neo-developmentalist stage, this tendency was reversed and 3 ) that the destinations of economic surplus in Argentina are largely unproductive and this conspires against the possibilities of developing a socially more equitable and potentially more diversified economy.
\end{abstract}

Keywords: Argentina, economic surplus, income distribution, neoliberalism, neo-developmentalism. 


\section{Resumo}

Este trabalho tem como objetivo estudar a evolução da economia política argentina comparando períodos convertibilidade (1991-2001) e postconvertibilidade (2002-2015), recuperando a análise efectuada pela teoria do excedente econômico (em suas versões estruturalista e marxista). Para este fim, são definidas e construídas séries estatísticas necessárias para esse propósito: o custo da reprodução social e o excedente económico, discriminando neste último caso usos produtivos (poupança e investimento) e improdutivos (fuga de capitais e consumo de luxo). A preparação destas séries é baseada em vários métodos de pesquisa e cálculo que vêm das Contas Nacionais, Internacionais e outras fontes de informação. Os resultados indicam: 1) o excedente econômico representa mais da metade do produto bruto interno, 2) na fase neoliberal houve uma deterioração das condições de reprodução social, enquanto que no segundo período neodesenvolvimentista esta tendência foi invertida e 3) que os destinos do excedente econômico na Argentina são em grande parte improdutivos e isso conspira contra as possibilidades de desenvolver uma economia socialmente mais justa e potencialmente mais diversificada.

Palavras-chave: Argentina, excedente econômico, distribuição de renda, neoliberalismo, neodesenvolvimentismo. 


\section{INTRODUCCIÓN}

La teoría del excedente económico (EE), surgida en la versión monopolista del marxismo (Baran, 1975; Baran \& Sweezy, 1988), señalaba que el capitalismo atravesaba una etapa específica de su desarrollo en la que no se verificaba la tendencia decreciente de la tasa de ganancia (que había señalado Marx, 1994), sino por el contrario, una propensión creciente de acumulación de riqueza por parte de los grandes capitales monopolistas. El excedente económico, a diferencia del plusvalor de Marx, no surgía exclusivamente de la explotación del trabajo, sino también de diversos mecanismos relacionados con la formación monopólica de precios. Tampoco se lo identificaba exclusivamente con el sistema capitalista, pues su análisis se empleaba para investigar las sociedades organizadas en otras formas de producción previas (como la esclavitud) o futuras (planificación socialista) (Santarcángelo \& Borroni, 2012).

Autores como Furtado (1978) y Prebisch (1981) aportaron una mirada estructuralista sobre el excedente económico, al considerar que su acumulación y destinos en América Latina eran el eje sobre el que se asentaba la estratificación social propia de los países latinoamericanos. El brasileño sugirió el cálculo del excedente económico a partir de la diferencia entre un costo de reproducción social (CRS, formado principalmente por las remuneraciones salariales) y el producto bruto interno (PBI), para identificar las tendencias verificadas en materia de condiciones de vida de las mayorías y el simultáneo acaparamiento de riqueza social por parte de las élites.

El análisis del excedente económico alcanzó su cenit hacia mediados del siglo 
pasado. Con el advenimiento del neoliberalismo, numerosas líneas críticas de investigación (como el estructuralismo radical y las teorías de la dependencia, que ponían el acento en las heterogéneas estructuras de clases, el poder, la extranjerización del aparato productivo y la apropiación desigual del excedente) fueron relegadas o desplazadas en el marco de la derrota de los proyectos socialistas y populares y el auge de la formación económica ortodoxa (Sociedad de Economía Crítica, 2014).

Este trabajo se propone estudiar la evolución de la economía política argentina comparando los períodos de convertibilidad (1991-2001) y postconvertibilidad (2002-2015), recuperando el análisis que brinda la teoría del EE y ofreciendo instrumentos para medirlo. El interés por estas etapas de la economía política argentina surge de las polémicas existentes respecto de las continuidades y rupturas entre el orden neoliberal (del cual la convertibilidad fue su "etapa superior") y el modelo neodesarrollista o populista que se desplegó durante los ciclos de gobiernos kirchneristas. El análisis no solo parte de la premisa de investigar la evolución de la riqueza social y la distribución de esta entre ambos proyectos, sino que pretende combinarlo con el concepto de régimen o patrón de acumulación.

Para lograr este propósito, el trabajo se organiza como sigue: después de esta breve introducción, en el segundo apartado, se hace revisión de literatura, en el tercer apartado se muestra la metodología, el periodo a revisar y los resultados. En el cuarto apartado se estiman el costo de reproducción social y el excedente económico entre 1991 y 2015. En el quinto apartado se discriminan los destinos del EE identificando sus repercusiones en materia productiva para el desarrollo económico. Finalmente se cierra el estudio con las conclusiones.

\section{REVISIÓN DE LA LITERATURA}

Desde los estudios de los economistas clásicos ha existido un especial interés por discutir los procesos de producción y la generación de riqueza en las sociedades modernas. Coincidiendo en la necesidad de poner el foco del debate económico en la esfera productiva, los principales autores de aquel tiempo reconocían la existencia de un excedente económico (EE) pasible de disputa entre las clases sociales. De acuerdo con Smith (2010) y Ricardo (2007), los salarios oscilaban en torno a un nivel de equilibrio (natural para el primero, de subsistencia para el segundo) que garantizaba la reproducción de los trabajadores pero no les permitía acumular riqueza, mientras que el producto excedente se dirimía entre capitalistas y terratenientes. Marx (1994) definió el salario como el pago correspondiente a la fuerza de trabajo, un valor determinado por componentes históricos y morales (en definitiva, por la dinámica de la lucha de clases) que posibilitaba la reproducción social de la clase trabajadora, mientras los capitalistas se apropiaban del producto exceden- 
te (plusvalor) generado en el proceso de trabajo.

Durante el siglo XX, pensadores estructuralistas y marxistas desarrollaron el enfoque del $\mathrm{EE}$, al que definieron como la diferencia entre lo que la sociedad produce y aquello que requiere para su reproducción ${ }^{1}$. A la luz de esta tarea, realizaron investigaciones para determinar un costo de reproducción social (CRS) que funcionara como parámetro para determinar el valor de las condiciones de vida básicas de las sociedades. Una vez obtenido dicho monto, podían estimar el EE, que resultaba de la diferencia entre el mismo y la producción total (PBI), variable que empleaban para alertar sobre la masa de recursos desaprovechados para potenciar el desarrollo de las fuerzas productivas. Furtado (1978) definió el CRS como el ingreso anual que la sociedad necesita para desarrollar sus tareas y necesidades fundamentales de alimentación, cuidado de la salud, seguridad social y educación, entre otras. Para determinarlo, sugería como referencia el nivel de vida de los trabajadores manuales no calificados (ya que remitía al sector de la población económicamente activa que menos se beneficiaba de la inversión destinada a formar el factor humano) y los gastos estatales de reproducción (vivienda, salud, educación).
Más adelante en el tiempo, varios autores emplearon distintos métodos de cuantificación del CRS: Lippit (1985) asoció los ingresos básicos de reproducción al consumo esencial, diferente del consumo innecesario (de lujo o superfluo); Danielson (1990) propuso como criterio la sumatoria de los ingresos mínimos (salarios de subsistencia que se pagaban en el agro) multiplicados por la cantidad de trabajadores productivos (del sector agrícola); Yeldan (1995) utilizó como representativos de los ingresos reproductivos los salarios en las empresas de baja escala (dado que la capacidad de organización sindical en las grandes firmas permitiría que dichos asalariados se apropiaran de parte del excedente); mientras que Somel (2003) lo estimó calculando el consumo esencial a partir del salario mínimo, vital y móvil.

Para el caso argentino, Sbattella (2001), inspirado en las ideas de Furtado, estimó el CRS (y luego el EE) durante el período 1980-2000, utilizando los ingresos promedio del decil 5 y los expandió a toda la población ocupada, dado que allí se encontraban los ingresos representativos de los trabajadores manuales no calificados. Posteriormente, Sbattella, Chena, Palmieri y Bona (2012) consideraron como componentes del CRS tanto a los elementos que permiten la reconstitución de la fuerza de trabajo como a

1 Si bien el análisis del excedente económico fue utilizado por los autores marxistas del capital monopolista (Baran, Sweezy) y sus seguidores (Poulantzas, Dobb, Mandel, etc.), otros pensadores marxistas (Shaikh, Mattick, Weeks, etc.) cuestionaron este enfoque al señalar que el abandono del concepto de plusvalor eliminaba una categoría clave del marco teórico de Marx. En efecto, mientras el plusvalor proviene estrictamente del trabajo bajo las formas capitalistas de producción, el EE incluye otros conceptos (intereses, rentas). Este cambio implica un viraje desde el análisis de los procesos de producción (explotación) hacia los de circulación o distribución de riqueza. Para más información acerca de las polémicas sobre el EE en el marxismo ver Bona (2016b). 
los que atañen al mantenimiento de la inactividad del trabajador y su reemplazo generacional, obteniendo de este modo un componente salarial (estimado con base en el salario de un trabajador manual no calificado) y un componente no salarial (financiado por el Estado y representado por bienes y servicios tales como salud, educación, vivienda, etc.). El cálculo del componente salarial fue estimado de acuerdo con los ingresos de los trabajadores manuales no calificados, promediando entre aquellos que pertenecen a los universos formal e informal. Para la población mayor, se empleó la jubilación mínima. A su vez, se incorporó la acción del Estado en el análisis del CRS, sumando las transferencias (subsidios al transporte y la energía, inversión pública en educación básica y salud) y restando los impuestos, de acuerdo con la presión tributaria.

A modo de síntesis, se presentan en la Tabla 1 las diferentes alternativas examinadas para estimar el CRS y el EE.

Tabla 1. Síntesis de las alternativas metodológicas para calcular el excedente económico

\begin{tabular}{|c|c|c|}
\hline Autor & Metodología de estimación del CRS y EE & País y fecha \\
\hline \multirow{5}{*}{$\begin{array}{l}\text { Phillips (en Baran \& } \\
\text { Sweezy, 1988) }\end{array}$} & $\begin{array}{l}\text { EE = ingresos de la propiedad + desperdicio del } \\
\text { proceso productivo + absorción de excedentes por } \\
\text { el Estado + penetración de campañas de ventas }\end{array}$ & \multirow{5}{*}{$\begin{array}{l}\text { EE.UU. } \\
(1949-1963)\end{array}$} \\
\hline & $\begin{array}{l}\text { Ingresos de la propiedad: ingresos del trabajo en } \\
\text { empresas no corporativas, gastos excesivos de } \\
\text { depreciación rentas intereses votros }\end{array}$ & \\
\hline & $\begin{array}{c}\text { Desperdicio en el proceso productivo: (propaganda, } \\
\text { gastos de investigación de mercado, comisiones por } \\
\text { ventas, etc.) }\end{array}$ & \\
\hline & $\begin{array}{l}\text { Absorción de excedente por parte del Estado: gasto } \\
\text { público }\end{array}$ & \\
\hline & Penetración de campañas de ventas: publicidad & \\
\hline \multirow{2}{*}{ Furtado (1978) } & EE = PBI - CRS - depreciación de capital & \multirow{2}{*}{ Sin estimaciones } \\
\hline & CRS: ingresos de trabajadores manuales no calificados & \\
\hline Prebisch (1981) & $\begin{array}{c}\text { EE = aumentos de productividad que quedan en } \\
\text { manos de las clases propietarias de los medios } \\
\text { productivos }\end{array}$ & Sin estimaciones \\
\hline \multirow[t]{2}{*}{ Lippit (1985) } & $\begin{array}{c}\text { EE = Beneficios + Rentas + Interés + la parte del } \\
\text { ingreso laboral que se destina a Consumo no } \\
\text { Esencial - Consumo Esencial }\end{array}$ & \multirow{2}{*}{$\begin{array}{c}\text { Turquía } \\
(1980-1992)\end{array}$} \\
\hline & $\begin{array}{l}\text { Consumo esencial: presupuesto mínimo para una } \\
\text { familia de la oficina de estadísticas de EEUU }\end{array}$ & \\
\hline
\end{tabular}


Continuación Tabla 1.

\begin{tabular}{|c|c|c|}
\hline \multirow{4}{*}{ Danielson (1990) } & $\begin{array}{c}\mathrm{EE}=\mathrm{PBI}-\text { salarios de subsistencia } \mathrm{x} \text { trabajadores } \\
\text { productivos - depreciación del capital }\end{array}$ & \multirow{4}{*}{$\begin{array}{l}\text { Jamaica } \\
(1962-1984)\end{array}$} \\
\hline & Salario de subsistencia: salarios en el sector agrícola & \\
\hline & Trabajo productivo: todo trabajo en el sector privado & \\
\hline & Trabajo improductivo: todo trabajo en el sector público & \\
\hline \multirow{2}{*}{ Yeldan (1995) } & $\begin{array}{c}\mathrm{EE}=\mathrm{PBI}-\text { salarios de subsistencia } \mathrm{x} \text { trabajadores } \\
\text { productivos }- \text { depreciación del capital }\end{array}$ & \multirow{2}{*}{$\begin{array}{c}\text { Turquía } \\
(1980-1992)\end{array}$} \\
\hline & $\begin{array}{l}\text { Salario de subsistencia: salarios de industrias privadas } \\
\qquad \text { de baja escala }\end{array}$ & \\
\hline \multirow{2}{*}{ Somel (2003) } & $\mathrm{EE}=\mathrm{PBI}-$ Consumo esencial & \multirow{2}{*}{$\begin{array}{c}\text { Turquía } \\
(1980-1996)\end{array}$} \\
\hline & Consumo esencial: salario mínimo oficial & \\
\hline \multirow[b]{2}{*}{ Sbattella (2001) } & $\mathrm{EE}=\mathrm{PBI}-\mathrm{CRS}$ & \multirow[b]{2}{*}{$\begin{array}{c}\text { Argentina } \\
(1980-2000)\end{array}$} \\
\hline & $\begin{array}{c}\text { CRS: ingresos decil } 5+\text { gasto público en salud, } \\
\text { educación y asistencia social gratuita - impuestos al } \\
\text { consumo }\end{array}$ & \\
\hline \multirow[b]{2}{*}{$\begin{array}{l}\text { Sbattella, Chena, } \\
\text { Palmieri \& Bona } \\
\text { (2012) }\end{array}$} & $\mathrm{EE}=\mathrm{PBI}-\mathrm{CRS}-$ depreciación del capital & \multirow[b]{2}{*}{$\begin{array}{c}\text { Argentina } \\
(2003-2008)\end{array}$} \\
\hline & $\begin{array}{c}\text { CRS: salario trabajadores no calificados + jubilaciones } \\
\text { mínimas + inversión pública en educación básica y } \\
\text { salud + subsidios a energía y transporte - presión } \\
\text { tributaria }\end{array}$ & \\
\hline
\end{tabular}

Siguiendo lo realizado por Bona (2018), se empleará como referencia principal la metodología de Sbattella et al. (2012) incorporando algunas modificaciones, ya que la misma permite captar volúmenes, tendencias y oscilaciones en las condiciones de reproducción de las clases subalternas, que varían dinámicamente en virtud de las relaciones de fuerza entre los grupos que disputan la riqueza, para luego calcular el EE.

\section{METODOLOGÍA}

Para estimar el costo de reproducción social, se empleará la metodología utilizada en Bona (2016a, 2018), para lo cual se dividirá el cálculo en tres módulos: el CRS salarial, el CRS jubilatorio y los componentes estatales:

$$
\begin{aligned}
\mathbf{C R S}_{\text {total }}= & C R S_{\text {salarial }}+C R S_{\text {jubilatorio }}+\text { gastos en educación básica, salud y subsidios a los } \\
& \text { usuarios residenciales de energía y transporte }- \text { presión tributaria }
\end{aligned}
$$

Para desarrollar el CRS salarial, se tomará como referencia el núcleo familiar (considerando la población de niños, hombres con menos de 65 años y mujeres con menos de 60), estimándolo a partir de los ingresos promedio declarados 
en la Encuesta Permanente de Hogares (EPH) del INDEC ${ }^{2}$. Por otro lado, para contemplar el universo de los desocupados, se les asignará el salario mínimo, vital y móvil (SMVM) ${ }^{3}$. Dado que las encuestas de hogares contemplan únicamente la población urbana, también se computará como ingreso reproductivo para los empleados rurales el SMVM, debido a que ellos se ubican entre los peor remunerados, en su mayoría con contratación precaria y muchas veces son de carácter estacional:

$\mathbf{C R S}_{\text {salarial }}=$ (salario promedio trabajadores formales $x$ cantidad de trabajadores formales) + [salario promedio trabajadores informales $x$ cantidad de trabajadores informales (en el ámbito urbano)] + [SMVMx (desocupados + trabajadores rurales)]

Para el CRS jubilatorio no se tomará en cuenta el hogar, sino un ingreso reproductivo por persona, ya que el sistema de seguridad social prevé una jubilación o pensión por persona mayor. Para ello, se toma como referencia la jubilación mínima, que se supone debe garantizar la reproducción de cada uno de los adultos mayores (contabilizada 13 veces, al igual que en el caso salarial):

\section{$\mathbf{C R S}_{\text {jubilatorio }}=$ jubilación mínima x cantidad de mayores cubiertos por el sistema previsio- nal anualmente.}

Los elementos que se consideran parte del costo de reproducción social son la educación primaria y secundaria y salud universal, a lo que cabe agregar los subsidios a los sectores económicos que se emplearon en la postconvertibilidad ${ }^{4}$.
Por último, para trazar un análisis de la acción estatal en la determinación del CRS, deben considerarse los impuestos que el Estado impone sobre los ingresos reproductivos ${ }^{5}$.

2 Instituto Nacional de Estadística y Censos de la República Argentina. Organismo oficial. La EPH se realiza de manera periódica desde la década del 80 y aunque varió metodológicamente entre 1991 y 2015, es la referencia fundamental para cualquier cálculo sobre condiciones de vida en Argentina.

3 De acuerdo con la Ley de Contrato de Trabajo, el salario mínimo vital y móvil se define como "la menor remuneración que debe percibir en efectivo el trabajador sin cargas de familia, en su jornada legal de trabajo, de modo que le asegure alimentación adecuada, vivienda digna, educación, vestuario, asistencia sanitaria, transporte y esparcimiento, vacaciones y previsión". Este valor se determina en forma tripartita en el marco del Consejo del Empleo, la Productividad y el Salario Mínimo, Vital y Móvil (Ministerio de Trabajo, Empleo y Seguridad Social).

4 El Gobierno nacional durante la postconvertibilidad subsidió las tarifas del transporte público terrestre y la energía residencial de manera masiva, abaratando significativamente los costos de vida para el conjunto de la población, en lo que representó un "salario indirecto".

5 La forma de estimar qué porcentaje de los mismos son utilizados para cancelar obligaciones con el fisco será identificar a qué decil de la población corresponden los ingresos representativos del CRS y, a partir de allí, observar qué porcentaje de ese ingreso corresponde al pago de impuestos (IVA, ganancias, etc.), utilizando la metodología de Santiere, Sabaini y Rossignolo (2000) y Gaggero y Rossignolo (2012). Al respecto, en ambos casos se aprecia que los valores de reproducción social corresponden al decil 5 de ingresos, donde la carga tributaria durante la convertibilidad alcanzaría el $29.59 \%$, mientras que la misma aumentaría a $32.49 \%$ en la postconvertibilidad. 


\section{El período por revisar y su propósito}

Hacia la última década del siglo XX, buena parte de las naciones de América Latina intensificó los procesos de apertura comercial, desregulación sectorial, privatización de empresas públicas y flexibilización (precarización) laboral, en lo que ha sido caracterizado como el período neoliberal (Guillén, 2007). Luego, hacia fines de los 90 y principios de la primera década del 2000, varios países (especialmente en Sudamérica) cambiaron de signo político, motivados por la impugnación (parcial o radical, dependiendo del caso) a dicho modelo, iniciando el ciclo de gobiernos progresistas, neodesarrollistas o de izquierda en la región (Katz, 2016).

Argentina representa uno de los ejemplos más nítidos de este tránsito entre dos etapas políticas y sociales, al calor de las transformaciones en las condiciones económicas internas (disputas sectoriales por la valorización del trabajo y el excedente económico) y externas (dinámica del mercado mundial y estrategias geopolíticas en la región).

El concepto que se utilizará para caracterizar ambos períodos es el de régimen o patrón de acumulación, que según Basualdo (2007): "alude a la articulación de un determinado funcionamiento de las variables económicas, vinculado a una definida estructura económica, una peculiar forma de Estado y las luchas entre los bloques sociales existentes" (p. 6).

Siguiendo esta lógica, la convertibilidad (1991-2001) resultó la "etapa superior" del proyecto neoliberal que se había instalado en Argentina desde 1976 por intermedio de la dictadura cívico-militar. Proyecto que tuvo como objetivo transferir ingresos del trabajo al capital, $\mathrm{y}$ fundamentalmente, hacia el sector más poderoso de este último, tal y como ocurrió de manera general en el mundo occidental (Harvey, 2005). Su consolidación en los años 90 se produciría en un momento muy particular del contexto internacional, durante el auge del Consenso de Washington ${ }^{6}$ y con posterioridad al descalabro económico de la hiperinflación de 1989-19907, que habilitaba un reclamo social de estabilidad, propicio para las recetas de ajuste. El proyecto tenía como propósito redistribuir el EE disciplinando a la clase trabajadora a partir de mayores niveles de explotación de la fuerza de trabajo (terciarizaciones, leyes de flexibilización laboral $\mathrm{y}$, fundamentalmente, un nuevo y elevado "piso" de desempleo que rápidamente superó los dos dígitos), incentivar las exportaciones "tradicionales" (a través de nuevas tecnologías en el sector agropecuario, tales como los paquetes de semillas transgénicas,

6 El llamado Consenso de Washington resumió en un conjunto de medidas de política económica (eliminación del déficit fiscal, privatizaciones de empresas públicas, apertura comercial, etc.) las recetas neoliberales (Harvey, 2005).

7 En 1989, la inflación en Argentina superó el 3000 \%, y en 1990, el 2000 \%. Estas variaciones en los niveles de precios tuvieron un significativo impacto en pobreza y desigualdad (Instituto Nacional de Estadística y Censos [INDEC], información de archivo). 
fertilizantes, desarrollo de maquinaria agrícola, instalación de plantas multinacionales de producción de los paquetes tecnológicos, nuevas leyes mineras e hidrocarburíferas, etc.) y recrear el ciclo de la valorización financiera sustentado en la dinámica del endeudamiento externo y la fuga de capitales locales al exterior (Basualdo, 2001). Para vehiculizar este programa se implementó la paridad cambiaria (además de habilitarse la libre convertibilidad del peso con el dólar estadounidense) y se impulsó la reforma del Estado que inauguraría un amplio proceso de privatizaciones de las empresas públicas (ambas por ley), (Ferrer, 2008).

El bloque de poder $^{8}$ que lideró esta agenda estuvo constituido por una "comunidad de negocios" entre los grupos económicos locales 9 y el gran capital transnacional, que concurrió al mercado argentino a través de las privatizaciones y con la garantía de la dolarización de sus activos por medio de la paridad cambiaria (Abeles, 1999). La hegemonía neoliberal alcanzada por este proyecto fue posible, en el orden interno, por la resolución (relativamente) exitosa de la hiperinflación ${ }^{10}$ y el pro- ceso de transformismo argentino por el cual las clases dominantes decapitaron la dirección política de las subalternas a través de la cooptación de sus líderes especialmente sindicales y partidarios (Basualdo, 2010)—. A ello cabe agregar el clima de época al calor de la caída del Muro de Berlín y el desmembramiento del bloque soviético (en cuyos países rápidamente se aplicó el programa aperturista, privatizador y desregulatorio) y las crisis sociales de los países latinoamericanos que no habían consolidado el programa neoliberal (Venezuela, Brasil, México, etc.).

Como buena parte de los países de la región, hacia fines de la década del 90, el orden neoliberal fue severamente cuestionado en Argentina. Por un lado, el sostenimiento de la paridad cambiaria exigía crecientes flujos de capitales vía endeudamiento externo de cada vez más dudosa capacidad de repago ${ }^{11}$, a lo que se sumaba una masiva fuga de capitales, que estalló ante las expectativas de devaluación en 2001 (más de USD 20000 millones). Por otra parte, la "comunidad de negocios" se quebró al potenciarse la recesión económica (1999-2001), dado que el régimen de acumulación susten-

8 El concepto de bloque de poder aquí utilizado proviene del análisis de Poulantzas (1979) y remite a la unidad contradictoria de las clases dominantes, dirigida por una clase o fracción hegemónica, donde: "[...] el concepto de hegemonía puede aplicarse a una clase o fracción dentro del bloque en el poder. Esa clase o fracción hegemónica constituye en efecto el elemento dominante de la unidad contradictoria de las clases o fracciones políticamente "dominantes", que forman parte del bloque en el poder" (p. 307).

9 El concepto de grupos económicos locales refiere a la "oligarquía diversificada", es decir, aquella porción de la histórica clase terrateniente argentina que, desde mediados del siglo XX, se lanzó al proceso de industrialización por sustitución de importaciones y logró comandar los principales resortes productivos del país, liderando la cúpula empresaria argentina (Basualdo, 2010).

10 En 1991, la inflación se redujo a menos del $100 \%$ anual, en 1992 no alcanzó el 20 \% y en 1993 fue inferior al $10 \%$ (INDEC, información de archivo).

11 En 2001, los organismos internacionales frenaron el crédito externo ante la creciente fuga de capitales verificada ese año, asestando un golpe decisivo a las condiciones de posibilidad del régimen de convertibilidad (Ferrer, 2008) 
tado en la valorización financiera ya no era capaz de garantizar condiciones y expectativas de rentabilidad sostenibles en el marco de la agudización de la contracción económica, a la que se sumaban conflictos sociales -derivados de la desindustrialización y el aumento del desempleo (Azpiazu \& Schorr, 2010) - y dificultades externas (como la desmejora de los términos de intercambio y los impactos de las crisis de Brasil - el principal socio comercial del país-, que devaluó su moneda en 1999, entre otras factores. Finalmente, los sectores populares, pauperizados por las políticas regresivas, se reinstalaron en el centro de la arena política a través de múltiples y diversas manifestaciones que venían in crescendo desde 1996 (Svampa, 2013). En ese contexto, se disolvía la hegemonía, porque el bloque dominante (ahora fragmentado) era incapaz de garantizar la estabilidad precedente. La crisis orgánica ${ }^{12}$ de 2001 se resolvió entonces cuando se dieron decisivos pasos para abandonar los fundamentos económicos de la convertibilidad e iniciar (sin la coherencia de un plan específico) un nuevo régimen de acumulación, reordenando el bloque de poder (López, 2016).

El nuevo giro en el patrón de acumulación resultó de un nuevo liderazgo hegemónico ejercido por los grupos económicos locales que impulsaron una brusca devaluación de la moneda (200\%) con pesificación (licuación) de sus deudas, el cese de pagos a los acreedores internacionales (default) y el congelamiento de las tarifas de los servicios públicos, entre otras aspectos (Varesi, 2014). Rápidamente, esto generó una masiva e inédita transferencia de ingresos del trabajo al capital (que se examinará más adelante) y la consecuente mejora en la posición relativa de los sectores productores de bienes (agroexportadores, industrias mercado internistas, construcción, etc.) en detrimento de los anteriores integrantes (aunque de manera subordinada) del bloque de poder neoliberal: el sector transnacional vinculado a los servicios (privatizadas y bancos extranjeros, perjudicados por una pesificación que desvalorizaba sus activos).

Lo que vendría luego, ya durante el ciclo de gobiernos kirchneristas (2003-2015), sería la sustanciación de este proyecto en la postconvertibilidad, abandonando la valorización financiera (ya que se alteraron las tasas de interés y se implementaron diferentes mecanismos de control de capitales) y aprovechando las nuevas condiciones externas favorables (superciclo de los commodities), lo que posibilitó, a la manera de una revolución pasiva, respuestas materiales y simbóli-

12 Siguiendo a Portelli (2011), la crisis orgánica se produce cuando "la clase dirigente deja de empujar a la sociedad entera hacia adelante" dando lugar a que el bloque ideológico que dio cohesión y hegemonía tiende a disgregarse. Las clases subalternas rompen toda ligazón con los dirigentes de los partidos tradicionales, expresándose una crisis de hegemonía en donde "muere lo viejo sin que pueda nacer lo nuevo" (p.121). 
cas a las demandas populares (Svampa, $2013)^{13}$. Se articuló entonces un nuevo tipo de Estado, con mayores concesiones concretas a las clases subalternas para sostener la naciente hegemonía, máxime después de la expropiación salarial resultante de la devaluación de $2002^{14}$.

Durante los gobiernos kirchneristas conviene sin embargo distinguir entre dos etapas de diferente coyuntura internacional y naturaleza política. La primera, vigente entre 2003 y 2008, en donde los nuevos "ganadores" habrían sido los sectores productores de bienes y, dentro de estos, los insertos en el mercado mundial (beneficiados por los bajos costos laborales, la virtual ausencia de competencia externa por depreciación de la moneda y el ritmo ascendente de los precios de los commodities). Aun así, y como consecuencia de lo anterior, el conjunto de las clases subalternas fue paulatinamente mejorando su posición relativa con la ayuda de la recuperación de la masa salarial total, principalmente por "efecto empleo" (la desocupación pasó del $22 \%$ en 2002 al $8.5 \%$ en 2008), y en segunda instancia, por "efecto ingreso" (aunque en este caso exclusivamente a cuenta de los trabajadores formales), a lo que cabe agregar la nueva impronta del gasto público social, que creció sostenidamente gracias a su mejora recaudatoria. Para los asalariados se asistió entonces a una tendencia positiva después de una fenomenal reducción de sus condiciones de vida postdevaluatoria.

El segundo período, que va de 2009 a 2015, se caracteriza por la potenciación de las medidas redistributivas que permiten inscribir al kirchnerismo dentro del grupo de gobiernos "populistas latinoamericanos". Ello se debió tanto a la dinámica de las luchas políticas por el manejo de la renta agropecuaria ${ }^{15}$ (que rápidamente reorganizaron el esquema de alianzas sociales) como al estallido de la crisis internacional (en septiembre del 2008), que resultaron decisivos para entender la deriva nacional-popular en el seno del bloque kirchnerista. Allí se verificó un alza decisiva en el gasto público social (abandonando el superávit fiscal registrado entre 2002 y 2010), la potenciación de los convenios colectivos de trabajo como vectores de las mejoras salariales — aunque crecientemente jaqueados por una inflación derivada de

13 Svampa (2013) recurre al concepto de revolución pasiva para entender a los sucesivos gobiernos kirchneristas: se trataría de una "tensión entre la transformación y la restauración en épocas de transición, que desemboca finalmente en la reconstitución de las relaciones sociales en un orden de dominación jerárquico" (p. 16) Esa reconstitución de las relaciones sociales implica que la clase dirigente neutraliza las demás capas sociales, especialmente a las subalternas, a través de mecanismos de cooptación tales como la utilización de personal dirigente en las estructuras ejecutivas del Estado, separando de hecho a los representantes de los grupos combativos, de sus bases de apoyo.

14 Los salarios reales promedio cayeron aproximadamente un $30 \%$ entre 2001 y 2003 (INDEC, información de archivo).

15 En 2008, el Gobierno nacional decidió fijar retenciones (impuestos) móviles a las principales exportaciones agropecuarias. La rebelión fiscal de los terratenientes rápidamente instaló un debate sobre la distribución del ingreso que dividió las aguas entre la oligarquía tradicional (junto a sectores medios que la apoyaron "solidariamente" contra el abuso del Estado) versus el Gobierno nacional y sus grupos sociales de apoyo (centralmente, el movimiento obrero organizado dentro de la CGT), (Basualdo et al., 2015). 
la puja distributiva (CIFRA, 2015)—, la estatización de algunas de las empresas antes privatizadas (el sistema de previsión social, la aerolínea de bandera, aguas, petróleo), la apropiación estatal de rentas (fundamentalmente agraria), el giro heterodoxo en el Banco Central, el establecimiento de controles de cambios y medidas arancelarias y paraarancelarias, entre otras (Basualdo, Manzanelli, Barrera, Wainer \& Bona, 2015).

La anterior "hegemonía neodesarrollista", que se había apoyado inicialmente sobre los sectores más concentrados del capital industrial, entró en crisis al calor de la agudización de la restricción externa (López, 2016). A partir de allí, la inestabilidad macroeconómica (inflación superior al $20 \%$ anual, déficit fiscal y luego comercial, caída de reservas internacionales del Banco Central) junto con la autonomía relativa (del carácter del Estado) bajo el proyecto kirchnerista respecto de los sectores dominantes que lo habían cobijado, recrudeció tensiones (que se analizarán en adelante) por el manejo del excedente económico durante el segundo mandato de Cristina Fernández (2011-2015).

\section{RESULTADOS}

El cálculo del costo de reproducción social que se detalla en el Anexo permite cuantificar el excedente económico, que surge de la fórmula: $\mathrm{EE}=\mathrm{PBI}-\mathrm{CRS}-$ depreciación del stock de capita ${ }^{16} \mathrm{y}$ cuyos datos se presentan a continuación.

Tabla 2. Evolución del producto bruto interno (PBI), el costo de reproducción social (CRS), la depreciación del stock de capital (dep. K) y el excedente económico (EE) en Argentina. Dólares constantes de 1991. Años 1991-2015.

\begin{tabular}{ccccc}
\hline Año & PBI & CRS & dep.K & EE \\
\hline 1991 & 166.104 & 60.133 & 19.983 & 85.988 \\
\hline 1992 & 202.146 & 73.329 & 22.333 & 106.484 \\
\hline 1993 & 222.904 & 84.065 & 24.883 & 113.956 \\
\hline 1994 & 236.497 & 87.305 & 25.796 & 123.396 \\
\hline 1995 & 230.572 & 81.763 & 25.877 & 122.932 \\
\hline 1996 & 236.250 & 77.666 & 25.432 & 133.152 \\
\hline 1997 & 248.420 & 80.882 & 25.764 & 141.774 \\
\hline 1998 & 249.722 & 83.429 & 27.204 & 139.089 \\
\hline
\end{tabular}

16 Para estimar la depreciación de la inversión realizada, se debe contabilizar el stock de capital de la economía y establecer qué volumen de recursos es necesario destinar a la reposición del mismo. Para ello se emplea la misma metodología que la seguida en Sbattella et al. (2012), basada en los trabajos de Coremberg (2009) y Keifman (2005). El stock de capital fue obtenido de los datos publicados por INDEC entre 1993 y 2006. Los valores de los años restantes fueron estimados con base en los niveles de inversión registrados. Como se desarrollará más adelante, no se deprecia todo el stock de capital de la construcción, ya que parte de esta es considerada suntuaria y no forma parte de la inversión productiva. 
Continuación Tabla 2.

\begin{tabular}{lllll}
\hline 1999 & 231.754 & 82.112 & 26.387 & 123.256 \\
\hline 2000 & 224.744 & 78.788 & 24.620 & 121.336 \\
\hline 2001 & 206.661 & 75.050 & 22.826 & 108.784 \\
\hline 2002 & 78.881 & 22.752 & 11.659 & 44.470 \\
\hline 2003 & 94.328 & 24.659 & 12.764 & 56.905 \\
\hline 2004 & 118.883 & 34.092 & 14.069 & 70.721 \\
\hline 2005 & 138.937 & 41.111 & 14.412 & 83.413 \\
\hline 2006 & 157.301 & 48.510 & 15.715 & 93.076 \\
\hline 2007 & 189.085 & 60.399 & 18.201 & 110.485 \\
\hline 2008 & 229.921 & 74.866 & 22.423 & 132.632 \\
\hline 2009 & 212.391 & 79.701 & 22.825 & 109.866 \\
\hline 2010 & 265.225 & 93.971 & 27.097 & 144.157 \\
\hline 2011 & 319.409 & 117.948 & 32.393 & 169.068 \\
\hline 2012 & 343.786 & 132.529 & 36.891 & 174.365 \\
\hline 2013 & 357.413 & 139.839 & 39.486 & 178.088 \\
\hline 2014 & 324.214 & 122.383 & 38.477 & 163.354 \\
\hline 2015 & 363.011 & 144.534 & 44.249 & 174.228 \\
\hline
\end{tabular}

Los resultados obtenidos se presentan tanto en dólares constantes de 1991 como en cuanto a la participación de cada variable en el PBI. Su evolución permite inferir algunas reflexiones respecto de las fases de acumulación de excedente económico y la evolución de las condiciones de reproducción social entre las etapas de convertibilidad y postconvertibilidad en Argentina.

En primer lugar, se observa que el EE creció considerablemente durante la fase expansiva (1991-1998) del régimen de convertibilidad, lo que refleja un fuerte incremento de los ingresos por parte de los sectores apropiadores de riqueza. Se trata de un proceso de veloz y exitosa salida de la crisis de acumulación que se manifestaba desde finales de la década del 80 , cuando todos los registros económicos y de actividad (producción, empleo, inversión) se habían desplomado en el marco de la hiperinflación de 1989-1990. Aquella situación significó un punto de partida especialmente bajo, desde donde la profundización de las políticas neoliberales de los años 90 "partían con ventaja" para anotar el despegue. El EE aumentó un $44 \%$ en dólares constantes entre 1991 y 1994, así como también se verificó una importante recuperación de los ingresos de reproducción social, que aumentaron un $45 \%$ en ese período (gracias a la estabilización de precios y la reparación salarial hacia niveles previos a la hiperinflación). Ambos registros posiblemen- 
te guarden relación con el apoyo, tanto de los grupos de altos ingresos como de una buena parte de los sectores populares, a la gestión menemista iniciada en 1989 y revalidada en 1995 con casi el $50 \%$ de los votos, dado que oficiaron como "base material" del proyecto hegemónico neoliberal (Pucciarelli, 2011).
Este proceso de crecimiento económico sumamente dinámico, sin embargo, se morigeró entre 1995 y 1998 (aun cuando continuó aumentando el EE), una vez superados los efectos expansivos (en inversión e ingresos fiscales) de las privatizaciones y el rebote postcrisis.

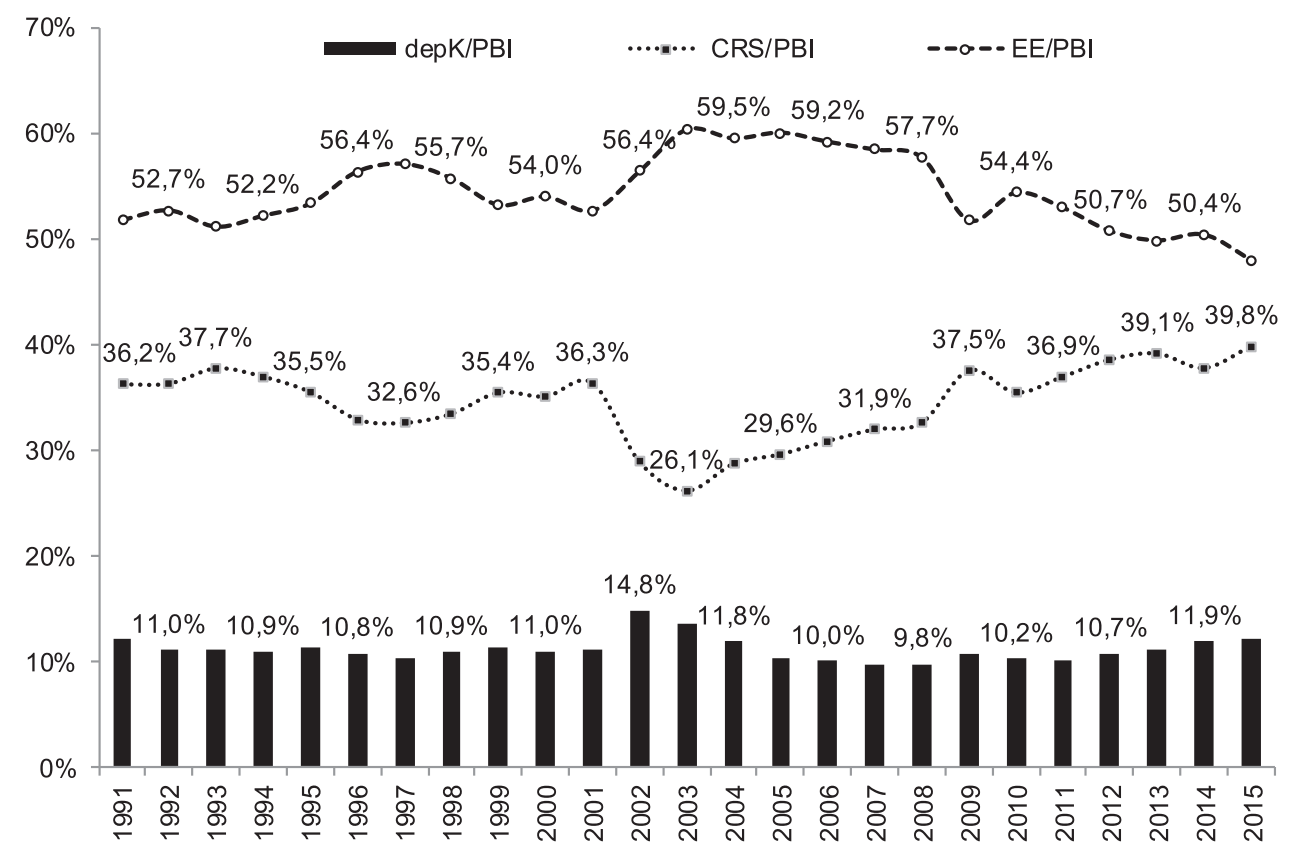

Figura 1. Evolución del costo de reproducción social (CRS), la depreciación del stock de capital (dep.K) y el excedente económico (EE) como porcentajes del PBI en Argentina. Años 1991-2015.

Fuente: elaboración propia con base en INDEC, ANSES, Ministerio de Economía y Finanzas Públicas de la Nación (Argentina).

Por su parte, la evolución de cada una de estas variables como porcentaje del PBI muestra que el EE resultó siempre superior al $50 \%$ del producto, lo que indica que Argentina es un país con enormes capacidades de generación de riqueza y satisfacción potencial de sus necesidades. El tramo de la convertibilidad que va de 1991 a 1998 mostró un proceso creciente de acumulación de excedente en relación con el producto, que alcanzó el $55.7 \%$ en 1997. Esta etapa se caracterizó por un doble fenómeno: crecimiento del PBI (con excep- 
ción de 1995) con caída del CRS, lo que indica una redistribución de la riqueza que va desde las clases subalternas (dependientes de los ingresos de reproducción social) hacia los sectores que se apropian del EE, en la medida en que aumentaron el desempleo y los ingresos de referencia de la reproducción social. En efecto, estos resultados eran lógicos en el marco de los procesos de flexibilización del universo laboral, apertura, desregulación, privatizaciones, etc., que generaron una heterogeneización salarial creciente, castigando especialmente a los trabajadores que integraban la base de la pirámide distributiva - ocupados precarizados y desempleados (Santarcángelo \& Schorr, 2001)—.

La tendencia descrita se revirtió desde 1999 hasta 2001, cuando la participación del EE en el producto disminuyó debido a la recesión económica, lo que terminó redundando en un incremento "espurio" del CRS, ya que este no se dio por reflejar mejores condiciones de vida de las clases subalternas ni disminuciones de la desigualdad, sino por efectos de la mayor caída en el PBI. Fue esta dinámica la que intensificó las contradicciones en el seno de la sociedad civil, sentando las bases materiales para el desarrollo de una crisis orgánica de 2001: la acumulación de EE se encontraba en retroceso y los sectores populares veían reducidos sus niveles reproductivos de manera sistemática desde 1999. Para buena parte de las clases dominantes (la nueva fracción hegemónica) interesadas en redistribuir regresivamente el ingre- so como estrategia de multiplicación de ganancias y posterior contratación de empleo "barato" —el bloque devaluador, que finalmente se impuso al alentar la eliminación de la Ley de Convertibilidad en enero de 2002 (Basualdo, 2010) — , la caja de conversión resultaba un corsé que hacía extremadamente difícil reducir los salarios en términos nominales.

De esta manera, con posterioridad al abandono de la convertibilidad, la devaluación de 2002 deprimió el volumen de todas las variables en valores constantes, aunque siendo especialmente sensibles los resultados en materia de reproducción social: el CRS disminuyó un $59 \%$ (el EE lo hizo en un $70 \%$ ). La depreciación del stock capital, debido al resabio acumulado, se contrajo un $48 \%$. Durante la primera etapa neodesarrollista (2002-2008) se produjo un incremento sustancial de todas las variables en el marco de la recuperación económica, aunque el del CRS fue mayor: el PBI y el EE se multiplicaron por 2.9 y 3 veces respectivamente, mientras que el CRS lo hizo por 3.3. Esta situación indica que los ingresos salariales, jubilatorios y la inversión pública social en educación y salud, se recuperaron un poco más rápidamente que las ganancias, rentas y beneficios, especialmente en el marco de la inédita expropiación salarial de 2002-2003. Cabe resaltar que este incremento del CRS obedeció más al "efecto empleo" (se generaron unos 4 millones de puestos de trabajo) que a ingresos. 
A pesar de lo anterior, en materia de la nueva estructura distributiva del producto, se trató del período de mayor regresividad: en el año 2003 el EE alcanzó su máximo nivel (60.3\%), en tanto que apenas un cuarto del mismo correspondió a la reproducción social (26.1\%), el registro más bajo de toda la serie bajo análisis. El promedio del EE/ PBI en la primera etapa de la postconvertibilidad (2002-2008) fue de $58.8 \%$, mientras que el del CRS/PBI solo del $29.8 \%$, cuando en la convertibilidad esos valores promediaron el $53.6 \%$ y el $35.3 \%$ respectivamente.

Finalmente, los cambios internos en la sociedad civil y política, junto con las decisivas mutaciones en el contexto internacional descritos anteriormente para caracterizar el segundo ciclo de gobiernos kirchneristas, se expresaron en la dinámica ascendente del CRS en este período, que se incrementó tanto en valores constantes como en relación con el PBI, alcanzando un máximo en 2015. En este contexto, resultaron decisivas las políticas estatales expansivas en períodos de recesión $(2009,2012$ y 2014), ya que allí el CRS continuó aumentando en dólares constantes (con excepción de 2014), marcando un "proceso de amortiguamiento de la crisis" para los sectores populares a partir del sistema de pro- tección social (no solo incrementos del gasto público, también expansión del empleo estatal, promoción del consumo en cuotas, programas de renovación de equipamiento del hogar, incentivos educativos, etc.).

Complementariamente, debe destacarse que la dinámica del EE ingresó en un terreno de relativo estancamiento durante el segundo mandato de Cristina Fernández: en 2015 el EE total (en dólares) solo era un $9.1 \%$ mayor al de 2012 , y su participación en el producto cayó a $48 \%$, el registro más bajo en toda la serie. Esta tendencia ponía en tensión las condiciones de reproducción de este esquema, porque las fuentes de excedente comenzaban a mermar inducidas por niveles salariales que pasaban a afectar la tasa de ganancia y la reversión de los términos de intercambio que redujeron la renta agropecuaria (INDEC, 2017). No resulta casual entonces que durante este tramo se haya erosionado el "consenso neodesarrollista" en el seno del bloque en el poder, por lo que los sectores hegemónicos dentro del mismo reclamaron la restauración de las condiciones de generación y distribución del EE del período 2002-2008 ${ }^{17}$.

17 Decía la Asociación Empresaria Argentina (que une a las mayores empresas locales y extranjeras del país) una vez concluida la gestión de Cristina Fernández: "No debe sorprender, entonces, que nuestra asociación se haya opuesto firmemente a la injerencia discrecional por parte del gobierno anterior en la vida de las empresas". (Palabras del presidente de AEA. Buenos Aires, 15 de diciembre, 2015). 


\section{LA DISCRIMINACIÓN DE LOS DESTINOS DEL EXCEDENTE ECONÓMICO}

De acuerdo con Paul Baran (1975) y Celso Furtado (1978), el análisis de los destinos del EE reviste una importancia central, ya que los grupos de poder, que acumulan riqueza en las sociedades periféricas, controlan el proceso económico y de este modo definen las modalidades de desarrollo al fijar la orientación de los recursos en fines productivos o improductivos. La tesis compartida por los teóricos de referencia indica que, mientras no se alteren los usos del EE, la condición de subdesarrollo tiende a perpetuarse reforzando el sistema centro-periferia.

Para avanzar en esta tarea, se discriminan los destinos productivos de los improductivos.

\section{Los usos productivos del excedente económico: inversión productiva $y$ ahorro interno}

Para buena parte del pensamiento estructuralista, la insuficiente y tecnológicamente atrasada inversión privada era un elemento condicionante de la heterogeneidad estructural y la consecuente desigualdad social en los países periféricos (Guillén, 2007). De ahí que dieran especial preponderancia al tratamiento de este aspecto en clave de disputa por el excedente económico.
En este sentido, el concepto de inversión productiva (IP) que se utiliza aquí intenta expresar con la mayor fidelidad posible las potencialidades de desarrollo económico y social de las inversiones en Argentina, a diferencia de los datos que brindan las Cuentas Nacionales. Para ello, se sigue una doble estrategia: por un lado, discriminar los componentes de la inversión bruta interna fija (IBIF) para inspeccionar cuáles contribuyen a mejorar la infraestructura social; por el otro, incorporar una serie de gastos públicos y privados que habitualmente no se consideran como inversión pero que, en los hechos, impulsan las capacidades de la sociedad ${ }^{18}$.

Uno de los aspectos centrales que surgen del análisis de la construcción es que alrededor de dos tercios son de carácter residencial y, dentro de ese universo, una parte considerable responde al segmento abc1, de muy altos ingresos. Diversos estudios (Instituto de Estadística y Registro de la Industria de la Construcción [IERIC], 2005; Baer, 2012) indican que durante la década del 90 , una porción del excedente derivado del proceso de acumulación se valorizó a través de la renta inmobiliaria, disparando la estratificación territorial a través de la proliferación de barrios cerrados, countries y torres de lujo. Posteriormente, luego de la devaluación de 2002 , el efecto riqueza positivo originado por la salida de la caja de conversión, generó que un grueso de los capitales no

18 La utilización de esta metodología se encuentra desarrollada en Sbattella et al. (2012). 
fugables (retenidos por los controles de cambios) y el rápido aumento del precio del suelo urbano y rural, potenciaran esta lógica, alentando la expansión de este sector. Como señala Prebisch (1981), este tipo de construcciones (suntuarias) refuerzan la estratificación social al presentarse como consumo imitador de los centros.

Por ello, se considerará como inversión productiva toda la construcción que no obedece a la edificación residencial del segmento abcl. Luego, se incorporarán aquellos gastos en educación superior (pública y privada), ciencia y técnica y cultura, con el propósito de dotar el concepto de inversión de componentes que potencien las capacidades técnicas, culturales y productivas de la sociedad, así como los subsidios a sectores económicos del Gobierno nacional para inversiones de capital. El cálculo de inversión productiva se resume en la Tabla 3.

Tabla 3. Evolución de los componentes de la inversión productiva (IP) y comparación con la inversión bruta interna fija (IBIF) en Argentina. Dólares constantes de 1991 y como porcentaje del producto bruto interno (PBI). Años 1991-2015.

\begin{tabular}{lcccccccccc}
\hline Año & $\begin{array}{c}\text { Const. } \\
\text { productiva }\end{array}$ & $\begin{array}{c}\text { Equipo } \\
\text { durable }\end{array}$ & $\begin{array}{c}\text { Edu. } \\
\text { sup. } \\
\text { univ. } \\
\text { pública }\end{array}$ & $\begin{array}{c}\text { Edu. } \\
\text { sup. } \\
\text { privada* }\end{array}$ & $\begin{array}{c}\text { Ciencia } \\
\text { y } \\
\text { técnica }\end{array}$ & $\begin{array}{c}\text { Cultura } \\
\text { y cult. } \\
\text { s/d }\end{array}$ & $\begin{array}{c}\text { Transf. } \\
\text { Ken } \\
\text { EyT }\end{array}$ & IP/PBI & $\begin{array}{c}\text { IBIF/ } \\
\text { PBI }\end{array}$ \\
\hline 1991 & 12.569 & 10.128 & 890 & 167 & 388 & 167 & 339 & - & $14,8 \%$ & $15,9 \%$ \\
\hline 1992 & 18.567 & 14.961 & 1.282 & 167 & 408 & 149 & 752 & - & $18,0 \%$ & $19,3 \%$ \\
\hline 1993 & 20.216 & 16.289 & 1.586 & 167 & 488 & 208 & 738 & - & $17,8 \%$ & $19,1 \%$ \\
\hline 1994 & 21.653 & 19.105 & 1.692 & 188 & 552 & 252 & 779 & - & $18,7 \%$ & $19,9 \%$ \\
\hline 1995 & 20.143 & 15.264 & 1.944 & 197 & 527 & 273 & 757 & - & $17,0 \%$ & $17,9 \%$ \\
\hline 1996 & 20.294 & 16.429 & 1.966 & 206 & 462 & 293 & 741 & - & $17,1 \%$ & $18,1 \%$ \\
\hline 1997 & 21.939 & 19.399 & 2.006 & 215 & 541 & 300 & 813 & - & $18,2 \%$ & $19,4 \%$ \\
\hline 1998 & 22.876 & 20.101 & 2.111 & 241 & 571 & 406 & 792 & - & $18,9 \%$ & $19,9 \%$ \\
\hline 1999 & 20.000 & 16.001 & 2.126 & 221 & 518 & 425 & 912 & - & $17,3 \%$ & $18,0 \%$ \\
\hline 2000 & 17.711 & 13.568 & 2.077 & 202 & 460 & 455 & 855 & - & $15,7 \%$ & $16,2 \%$ \\
\hline 2001 & 15.102 & 9.746 & 1.974 & 208 & 393 & 418 & 773 & - & $13,8 \%$ & $14,2 \%$ \\
\hline 2002 & 3.913 & 3.609 & 636 & 65 & 144 & 130 & 241 & - & $11,1 \%$ & $12,0 \%$ \\
\hline 2003 & 5.823 & 5.415 & 752 & 81 & 191 & 152 & 272 & - & $13,4 \%$ & $15,1 \%$ \\
\hline 2004 & 7.423 & 7.540 & 817 & 92 & 222 & 182 & 364 & 35 & $14,0 \%$ & $15,9 \%$ \\
\hline 2005 & 9.302 & 9.957 & 1.079 & 141 & 283 & 228 & 496 & 99 & $15,5 \%$ & $17,4 \%$ \\
\hline 2006 & 11.106 & 11.938 & 1.374 & 189 & 350 & 269 & 621 & 388 & $16,7 \%$ & $18,3 \%$ \\
\hline 2007 & 13.588 & 16.229 & 1.771 & 271 & 447 & 349 & 836 & 454 & $18,0 \%$ & $19,5 \%$ \\
\hline & & & & & & & & & & \\
\hline
\end{tabular}


Continuación Tabla 3.

\begin{tabular}{lllllllllll}
\hline 2008 & 16.352 & 18.830 & 2.286 & 371 & 547 & 405 & 1.241 & 892 & $17,8 \%$ & $19,0 \%$ \\
\hline 2009 & 13.018 & 13.289 & 2.567 & 438 & 615 & 453 & 1.282 & 621 & $15,2 \%$ & $15,6 \%$ \\
\hline 2010 & 16.712 & 18.821 & 3.060 & 528 & 716 & 574 & 1.314 & 999 & $16,1 \%$ & $16,6 \%$ \\
\hline 2011 & 20.539 & 23.353 & 3.756 & 631 & 853 & 703 & 1.706 & 1.015 & $16,5 \%$ & $17,2 \%$ \\
\hline 2012 & 21.429 & 21.678 & 4.191 & 704 & 998 & 791 & 1.894 & 1.390 & $15,4 \%$ & $15,9 \%$ \\
\hline 2013 & 21.493 & 23.322 & 4.404 & 801 & 1.110 & 916 & 1.885 & 3.010 & $15,9 \%$ & $16,3 \%$ \\
\hline 2014 & 20.590 & 20.164 & 4.009 & 728 & 1.038 & 805 & 1.875 & 3.866 & $16,4 \%$ & $16,0 \%$ \\
\hline 2015 & 22.985 & 22.175 & 4.788 & 820 & 1.166 & 918 & 2.605 & 2.959 & $16,1 \%$ & $15,9 \%$ \\
\hline \multicolumn{7}{c}{ *El cálculo de la educación superior privada se realiza aplicando el gasto por estudiante de las } \\
universidades públicas a la cantidad de estudiantes de las universidades privadas. & &
\end{tabular}

Fuente: elaboración propia con base en datos de ASAP, INDEC y Anuario de Estadísticas Universitarias (AEI).

Como lo indican los datos obtenidos, se destaca el crecimiento de las transferencias estatales para gastos de capital en energía y transporte realizadas en la postconvertibilidad para sostener el valor de las tarifas de servicios públicos, además de la dinámica de la inversión en educación (especialmente universitaria) y cultura. Aun así, en muchos casos la IP resulta menor que la inversión bruta interna fija que contabilizan las Cuentas Nacionales, ya que el peso de la construcción residencial suntuaria resulta en muchos casos superior a todos los demás componentes incorporados (con excepción de 2014 y 2015).
Por otra parte, como uso productivo del EE se considera el ahorro, que representa una necesidad para la futura inversión, así como la fuente de recursos para el crédito presente. Este concepto será contabilizado a partir de los registros más básicos de depósito que contabilizan los bancos: cuentas corrientes, cajas de ahorro, plazos fijos y otras de mayor grado de exposición en los balances del sistema financiero consolidado, de donde el valor calculado indicará el movimiento de fondos acumulados (o extraídos) del sistema financiero local (tanto en moneda nacional como extranjera) interanualmente. 
Tabla 4. Evolución de los usos productivos del excedente económico en Argentina. Millones de dólares constantes y como porcentaje del excedente económico total (EE). Años 1991-2015.

\begin{tabular}{|c|c|c|c|}
\hline Año & Inversión productiva & Ahorro interno & Usos productivos/EE \\
\hline 1991 & 24.648 & 7.494 & $37,4 \%$ \\
\hline 1992 & 36.286 & 8.265 & $41,8 \%$ \\
\hline 1993 & 39.692 & 10.697 & $44,2 \%$ \\
\hline 1994 & 44.220 & 5.866 & $40,6 \%$ \\
\hline 1995 & 39.106 & -1.106 & $31,8 \%$ \\
\hline 1996 & 40.391 & 7.215 & $35,8 \%$ \\
\hline 1997 & 45.212 & 10.508 & $39,3 \%$ \\
\hline 1998 & 47.097 & 7.702 & $39,4 \%$ \\
\hline 1999 & 40.203 & 1.942 & $34,2 \%$ \\
\hline 2000 & 35.328 & 3.029 & $31,6 \%$ \\
\hline 2001 & 28.616 & -10.397 & $26,3 \%$ \\
\hline 2002 & 8.739 & 1.357 & $22,7 \%$ \\
\hline 2003 & 12.686 & 2.879 & $27,4 \%$ \\
\hline 2004 & 16.676 & 1.514 & $25,7 \%$ \\
\hline 2005 & 21.585 & 4.073 & $30,8 \%$ \\
\hline 2006 & 26.236 & 4.842 & $33,4 \%$ \\
\hline 2007 & 33.945 & 6.393 & $36,5 \%$ \\
\hline 2008 & 40.925 & 2.498 & $32,7 \%$ \\
\hline 2009 & 32.283 & 5.627 & $34,5 \%$ \\
\hline 2010 & 42.725 & 9.349 & $36,1 \%$ \\
\hline 2011 & 52.555 & 10.127 & $37,1 \%$ \\
\hline 2012 & 53.074 & 12.997 & $37,9 \%$ \\
\hline 2013 & 56.942 & 12.694 & $39,1 \%$ \\
\hline 2014 & 53.074 & 12.280 & $40,0 \%$ \\
\hline 2015 & 58.414 & 21.158 & $45,7 \%$ \\
\hline
\end{tabular}

Fuente: elaboración propia con base en datos del BCRA e INDEC. 
Como se desprende de los datos obtenidos, los destinos productivos del EE siempre resultan minoritarios en relación con los improductivos, y promediaron el $36.6 \%$ entre 1991 y 2001 y $34.3 \%$ entre 2002 y 2015. Distinguiendo entre subetapas: el sexenio 91-96 registró un $38.6 \%$, entre 1997 y 2001 cayó a $34.2 \%$, el peor período fue el del inicio de la postconvertibilidad (29.9\% en 2002-2008) y retornó a las mejores marcas de la convertibilidad entre 2009 y $2015(38.6 \%)$.

\section{Los usos improductivos del excedente económico: fuga de capitales, compra de bienes de consumo importados, construcción residencial suntuaria y consumo no esencial}

La fuga de capitales locales al exterior ha sido tratada como uno de los destinos del EE más ineficientes para los teóricos estructuralistas y marxistas del subdesarrollo. Algunas de sus principales consecuencias son: menor recaudación fiscal, pérdida de recursos potencialmente utilizables para inversiones $y$, como secuela de ello, mayores niveles de regresividad distributiva.
El análisis de la fuga de capitales en Argentina en el período bajo estudio por parte de varios autores (Gaggero, Rúa \& Gaggero, 2013; Basualdo et al., 2015) coincide en enmarcarla dentro de las lógicas del capitalismo a escala global surgidas desde la instauración del neoliberalismo (mediados de los años 70 del siglo pasado) bajo el amparo de la expansión del capital financiero. Los datos que se presentarán dan cuenta de la persistencia de la misma tanto durante el período de convertibilidad como de postconvertibilidad, aun a pesar de los cambios registrados en el patrón de acumulación ${ }^{19}$.

Por otro lado, la adquisición de bienes de consumo importados (en una economía que es autosuficiente en acervos de este tipo) es un destino del EE que puede ser calculado a partir de los datos de Cuentas Nacionales y brinda información sobre la imitación que hacen las élites del patrón de consumo de los países centrales (Prebisch, 1981). De esta manera, su discriminación permite dar razón de qué porción del EE se filtra hacia demandas mayormente improductivas $^{20}$.

19 La particularidad del caso argentino es que durante la llamada valorización financiera (1976-2001) la fuga tuvo una relación simbiótica con la deuda externa, mientras que durante la postconvertibilidad si bien se agotó aquella dinámica (por la restricción al crédito internacional, el cambio en los niveles de las tasa de interés locales y externas y los controles cambiarios, entre otros factores), el drenaje de divisas de la economía argentina no se detuvo, aunque pasó a ser financiado por los excedentes comerciales. Su dinámica entre 2002 y 2015 obedeció a un conjunto de aspectos que se pueden resumir en la estrategia de dolarización de las ganancias y rentas de los sectores apropiadoras del EE heredadas de la valorización financiera, las expectativas devaluatorias bajo el contexto de inflación superior a los dos dígitos desde 2007, la crisis internacional disparada en septiembre de 2008 que generó una rápida "fuga a la calidad" por parte de los sectores de altos ingresos y, a su vez, el salto en la puja distributiva durante el último ciclo de gobiernos kirchneristas, que explica la sucesión de corridas cambiarias, retenciones de cosechas de mercancías de exportación, proliferación de tipos de cambios paralelos (dólar negro, dólar bolsa), entre otras respuestas a las medidas de política económica establecidas desde 2011 (Basualdo et al., 2015).

$20 \mathrm{Si}$ bien hay una porción de los bienes de consumo importados que corresponde a productos farmacéuticos, la misma ronda el $10 \%$ de este tipo de importaciones. A su vez, parte de esos productos farmacéuticos corresponde a consumo suntuario (lociones, cremas, productos de tocador, etc.). 
Otro uso improductivo del EE por discriminar es la mencionada construcción residencial privada que no contribuye a fines productivos, sino que funciona como una reserva de valor o de estratificación social. Al respecto, resta consignar qué porción de la misma debe contabilizarse como suntuaria. Para ello, se estimó el porcentaje de la construcción privada residencial orientada a los sectores de mayores ingresos y se restó del total construido ${ }^{21}$.

Por último, hay que aclarar que la proporción de EE no discriminada por los componentes antes calculados será considerada como consumo no esencial, ya que se trata de una porción innecesaria para atender las necesidades sociales $(\mathrm{CRS})^{22}$. Los usos improductivos del EE se presentan en la Tabla 5.

Tabla 5. Evolución de los destinos improductivos del excedente económico en Argentina. Millones de dólares constantes y como porcentaje del excedente económico total (EE). Años 1991-2015

\begin{tabular}{cccccc}
\hline Año & $\begin{array}{c}\text { Fuga de } \\
\text { capitales }\end{array}$ & $\begin{array}{c}\text { Compra bienes } \\
\text { importados de } \\
\text { consumo }\end{array}$ & $\begin{array}{c}\text { Construcción } \\
\text { suntuaria }\end{array}$ & $\begin{array}{c}\text { Consumo no } \\
\text { esencial }\end{array}$ & $\begin{array}{c}\text { Usos } \\
\text { improductivos/EE }\end{array}$ \\
\hline 1991 & -14 & 1.514 & 3.714 & 48.618 & $62,6 \%$ \\
\hline 1992 & -4.587 & 3.110 & 5.486 & 53.337 & $58,2 \%$ \\
\hline 1993 & -33 & 3.324 & 5.974 & 54.270 & $55,8 \%$ \\
\hline 1994 & 5.243 & 3.589 & 6.397 & 58.080 & $59,4 \%$ \\
\hline 1995 & 12.997 & 2.836 & 5.952 & 62.040 & $68,2 \%$ \\
\hline 1996 & 8.049 & 3.110 & 5.996 & 68.391 & $64,2 \%$ \\
\hline 1997 & 7.900 & 3.848 & 6.781 & 67.526 & $60,7 \%$ \\
\hline 1998 & 5.896 & 4.038 & 6.805 & 67.551 & $60,6 \%$ \\
\hline 1999 & 12.920 & 3.679 & 5.747 & 58.764 & $65,8 \%$ \\
\hline 2000 & 3.444 & 3.645 & 5.112 & 70.778 & $68,4 \%$ \\
\hline 2001 & 16.710 & 3.075 & 4.455 & 55.928 & $73,7 \%$ \\
\hline 2002 & 4.472 & 861 & 1.913 & 27.130 & $77,3 \%$ \\
\hline 2003 & 10.391 & 1.300 & 3.041 & 26.609 & $72,6 \%$ \\
\hline 2004 & 6.085 & 1.803 & 3.931 & 40.712 & $74,3 \%$ \\
\hline 2005 & -3.810 & 2.205 & 4.850 & 50.704 & $69,2 \%$ \\
\hline
\end{tabular}

21 De acuerdo con Baer (2012), tomando como referencia la ciudad de Buenos Aires, entre 1991 y 2002 , el $39.7 \%$ de las construcciones fueron lujosas o suntuarias, en tanto que el resto se dividió entre confortables y básicas. A falta de datos nacionales sobre los tipos de construcción, se puede inferir que esa proporción puede aproximarse a los valores de todo el país. El mismo trabajo constata que el porcentaje de viviendas lujosas y suntuarias creció a $52.7 \%$ entre 2003 y 2008, como resultado del fenómeno de construcción como reserva de valor desde la salida de la convertibilidad. Al respecto, la proliferación antes citada de countries y barrios cerrados en toda la etapa 19912012 parece marcar la pauta de una segregación urbana sostenida en el AMBA (y posiblemente este fenómeno se haya expandido hacia el interior del país en los últimos años).

22 Este tipo de consumo no solo lo realizan los sectores de ingresos altos (que tienen una gran proporción de consumo suntuario), sino además trabajadores que superan los niveles de reproducción social y demandan bienes y servicios de lujo. 
Continuación Tabla 5.

\begin{tabular}{cccccc}
\hline 2006 & 3.154 & 2.681 & 5.790 & 50.379 & $66,6 \%$ \\
\hline 2007 & 8.816 & 3.420 & 7.085 & 50.816 & $63,5 \%$ \\
\hline 2008 & 7.670 & 3.979 & 8.526 & 69.036 & $67,3 \%$ \\
\hline 2009 & 961 & 3.217 & 6.787 & 60.989 & $65,5 \%$ \\
\hline 2010 & 10.445 & 4.128 & 8.604 & 68.912 & $63,9 \%$ \\
\hline 2011 & 13.447 & 4.867 & 11.200 & 76.871 & $62,9 \%$ \\
\hline 2012 & 9.707 & 4.325 & 11.409 & 82.855 & $62,1 \%$ \\
\hline 2013 & 2.447 & 4.349 & 13.405 & 88.242 & $60,9 \%$ \\
\hline 2014 & 4.371 & 3.785 & 11.055 & 78.796 & $60,0 \%$ \\
\hline 2015 & 4.313 & 3.896 & 12.341 & 74.102 & $54,3 \%$ \\
\hline
\end{tabular}

Fuente: elaboración propia con base en INDEC, Anuario de Estadísticas Universitarias y Banco Central de la República Argentina

LA DINÁMICA DE LOS USOS DEL junta permitirá observar algunos de EXCEDENTE ECONÓMICO los rasgos salientes de la etapa de la convertibilidad y su continuadora, con

La presentación de los destinos del el propósito de verificar los cambios y excedente económico de forma contendencias registrados a luz del análisis del desarrollo económico periférico.

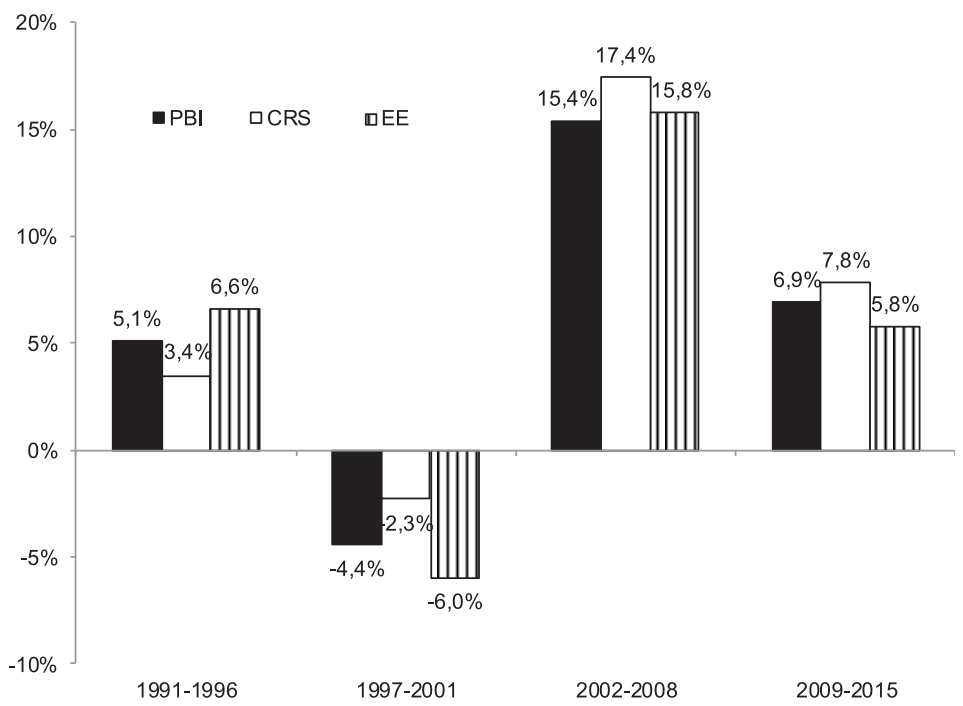

Figura 2. Tasa de crecimiento anual acumulativa del costo de reproducción social, los usos productivos e improductivos del excedente económico y la depreciación del stock de capital en Argentina. Dólares constantes de 1991 per cápita. Períodos 1991-1996, 1997-2001, 2002-2008 y 2009-2015. 
Los resultados indican que en Argentina los destinos del EE sufrieron importantes transformaciones a lo largo de los dos patrones de acumulación bajo análisis. Al respecto, si bien la primera etapa de la convertibilidad (1991-1996) se caracterizó por un importante crecimiento (en dólares constantes per cápita) de todas las variables bajo estudio, la que más lo hizo es aquella que compila los usos improductivos del EE (7.1\% anual acumulativo). También los destinos productivos aumentaron considerablemente (5.8 \% a. a.), mientras que el CRS, si bien lo hizo, registró un ritmo mucho menor (3.8 \% a.a.). Ello explica que el crecimiento de la etapa "dorada" de la convertibilidad fuera "desigualador", porque si bien se recompusieron las condiciones materiales de las clases subalternas, lo hicieron como resultado de la recuperación posthiperinflación, en tanto que el EE creció significativamente más. Estas evidencias cuestionan los balances sociales positivos de la convertibilidad que fueran hegemónicos en los años 90 (Fundación de Investigaciones Económicas Latinoamericanas [FIEL], 1999).

Por su parte, la IP aumentó tanto a causa de las privatizaciones como de la dinámica de la construcción residencial y la sostenida ampliación del ahorro (derivado de la estabilidad cambiaria, garantizada por la caja de conversión). En cambio, en los usos improductivos resultaron claves la demanda de importaciones, la construcción suntuaria y el consumo no esencial, mientras que la fuga de capitales solo irrumpió hacia 1994-1996, ya en el marco de su primera crisis (del Tequila, en 1995) y el ocaso del ingreso de capitales por venta de activos del Estado. De esta manera, el primer ciclo de la convertibilidad (1991-1996) se cerró con el tándem (IP+Ahorro interno) en declive con relación al producto, mientras los destinos negativos del EE comenzaron a superar en participación al CRS.

Las tendencias regresivas advertidas en esa primera etapa, aun en el marco del significativo crecimiento del producto, se multiplicaron hacia el período de crisis (1999-2001), cuando se produjo un derrumbe de los usos productivos del EE: cayeron a una tasa anual acumulativa del $13 \%$, debido al drenaje de depósitos y la ausencia de perspectivas rentables en sectores demandantes de equipamiento y tecnología. Los usos improductivos disminuyeron en valores constantes al igual que los ingresos reproductivos $(-2.3$ y $-2.2 \%$ respectivamente), aunque si se mira el cuadro en materia de distribución del producto, la imagen puede resultar "engañosa": el CRS incrementó su peso en el mismo de manera espuria, a causa de la mayor caída en el EE total. A diferencia de los planteamientos que anticipaban un proceso duradero de crecimiento y estabilidad (Artana, 2001), estos aspectos dan cuenta del agotamiento del modelo de convertibilidad tanto para los sectores populares como para los grupos apropiadores del EE, ya que (si bien cayeron en términos constantes) los destinos 
improductivos ganaron participación en el PBI y la fuga de capitales locales al exterior resultó la "válvula de escape" de esta riqueza.

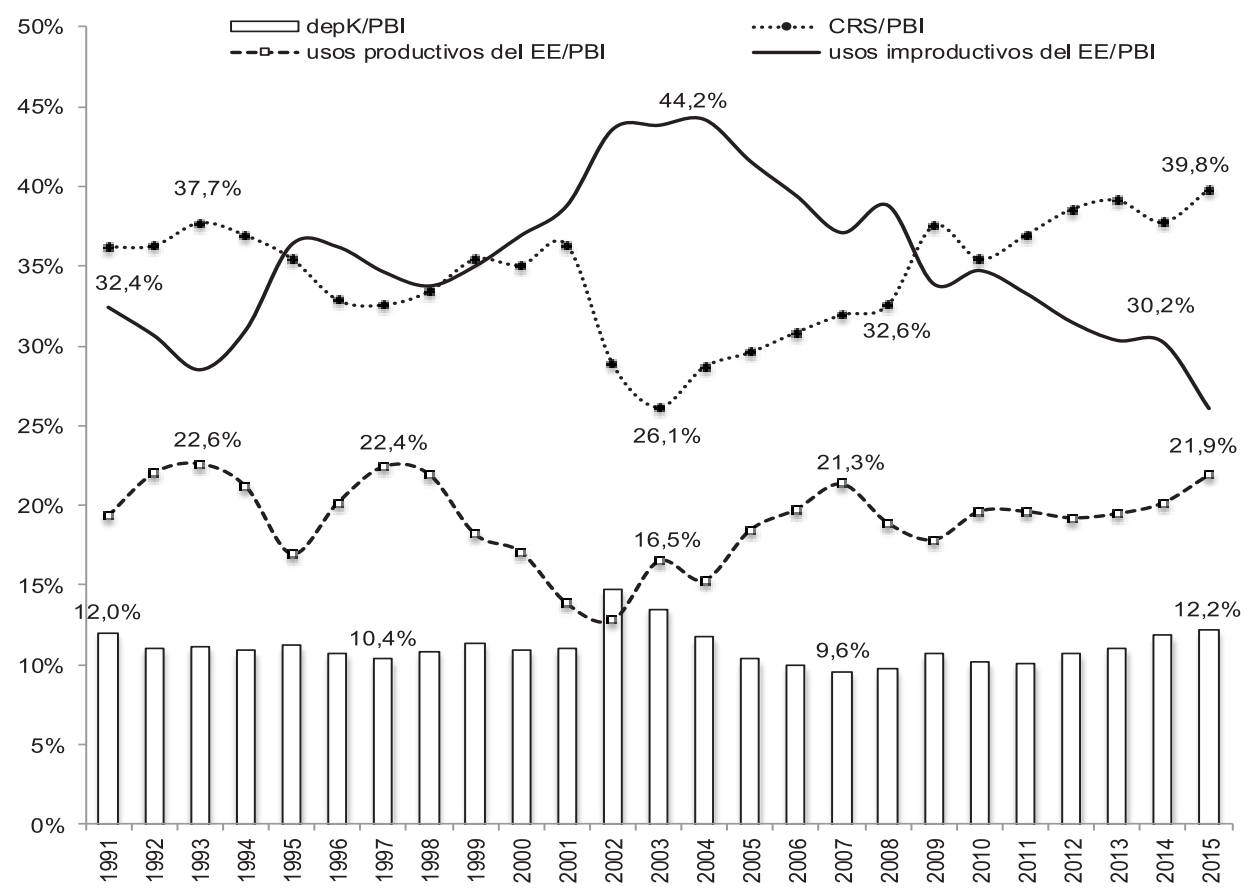

Figura 3. Evolución del costo de reproducción social (CRS), los destinos productivos e improductivos del excedente económico (EE) y la depreciación del stock de capital en porcentaje del producto bruto interno (PBI) en Argentina. Años 1991-2015.

La devaluación abrió un nuevo escenario, especialmente negativo para las clases subalternas y beneficioso para el bloque de poder que hegemonizó la primera etapa del ciclo de postconvertibilidad: el gran capital productivo anotó un crecimiento sustancial que permitió un vertiginoso incremento de la inversión productiva $(+22 \%$ de crecimiento anual acumulativo en dólares constantes per cápita) así como de los siempre predominantes destinos improductivos del EE (+13\% a.a.). El CRS, después de una "expropiación" derivada de la devaluación en 2002, también anotó mejoras significativas $(+17 \%$ a.a. $)$, aunque el cuadro distributivo estaba moldeado por una inédita regresividad que solo se vería alterada durante el segundo ciclo de gobiernos kirchneristas. Los usos improductivos entre 2002 y 2008 promediaron el $41.2 \%$ del PBI, el CRS el $29.8 \%$, y los productivos solo el $17.6 \%$. Si bien algunos autores señalan que esta 
fue la etapa exitosa del ciclo neodesarrollista (Curia, 2014), este esquema, hecho a la medida del bloque de poder dominante, no era propenso a habilitar mejoras distributivas, lo que se puso en tensión después de los acontecimientos de septiembre del 2008 que modificaron la naturaleza del proyecto económico vigente hasta ese momento.

Para entender el segundo ciclo de gobiernos kirchneristas, tomando distancia de quienes lo consideran una deriva populista errática (Damill \& Frenkel, 2015), expresa en cambio las disputas por forjar un patrón de acumulación con mayor dinamismo de los ingresos reproductivos y las transferencias estatales para tal fin. Se expandió más que ninguna otra variable el CRS/PBI (por componentes salariales, jubilatorios e inversión pública social) y cayeron los destinos improductivos del EE (30\% del producto en 2015), especialmente el consumo no esencial, como resultado del establecimiento de controles cambiarios y medidas arancelarias, monetarias y fiscales. Ello también se verifica si se mide en dólares constantes per cápita, al observar que el CRS creció a una tasa acumulativa de $7.8 \%$ y los usos productivos lo hicieron al $10 \%$. Los destinos negativos del EE tan solo aumentaron a un ritmo de $2.2 \%$. Por este motivo, el CRS/PBI alcanzó su promedio más alto en comparación con las otras etapas, llegando al $39.8 \%$, mientras que los destinos improductivos llegaron al $26.1 \%$. A pesar de lo anterior, el tándem
(IP+Ahorro)/PBI promedió el $19.7 \%$ entre 2009 y 2015 , lo que alertaba sobre la ausencia de cambios estructurales en la matriz productiva argentina heredada del proyecto neoliberal (Cantamutto, Schorr \& Wainer, 2016).

\section{CONCLUSIONES}

Este trabajo se propuso examinar la evolución de la economía política argentina entre 1991 y 2015, período en que se pusieron en marcha dos patrones de acumulación: el proyecto neoliberal bajo al régimen de convertibilidad (1991-2001) y la etapa neodesarrollista o populista bajo los ciclos de gobiernos kirchneristas (2002-2015). Para ello, se recuperó la teoría del excedente económico y se propuso un esquema metodológico bajo la construcción de variables propias.

Los resultados obtenidos indican que el volumen del excedente económico generado en Argentina es elevado y dinámico. En ambos proyectos político-sociales se verifica que la economía logró despegar después de dos crisis muy profundas, como lo fueron la de la hiperinflación de 1989/90 y la verificada hacia el cierre de la convertibilidad (y posterior devaluación) de 1999-2002. La proporción del EE con relación al PBI, oscilando entre el $48 \%$ (2015) y el $60.3 \%$ (2003) a lo largo de toda la serie, ilustra la enorme riqueza creada en este período y las altas potencialidades de redistribución de la misma, hecho que refuta a los teóricos ortodoxos que 
argumentan la necesidad de crecer para después repartir (a modo de derrame).

Durante la fase neoliberal, el país transitó un sendero de deterioro (prácticamente) sistemático de las condiciones de vida de las clases subalternas (CRS), mientras el grueso del EE generado fue utilizado improductivamente, tanto en fuga de capitales como en consumo no esencial, construcción suntuaria y demanda de bienes importados. Las políticas de apertura, desregulación, privatizaciones y flexibilización laboral debilitaron el mundo del trabajo, pero las transferencias del capital no se tradujeron en las inversiones productivas prometidas. Cuando la crisis estalló a causa de la combinación de las demandas de las clases subalternas, el agotamiento de las condiciones que permitían la valorización financiera y el "quiebre de la comunidad de negocios" (grupos económicos locales y capital extranjero), la devaluación disparó un cuadro regresivo inédito sobre el que se asentó el nuevo modelo de crecimiento, diseñado a la altura de los grandes capitales productores de bienes.

En el primer período de la postconvertibilidad (2002-2008) se puso en marcha ese nuevo esquema donde "todos ganaban": se recuperó el CRS y lo hizo más la inversión, aunque el grueso del PBI seguía destinándose al gasto improductivo, especialmente por la construcción suntuaria, la persistencia de la fuga de capitales y un importante crecimiento del consumo no esencial derivado de la desigualdad de ingresos.

Hacia septiembre del 2008 ese consenso hegemónico neodesarrollista pareció afrontar límites, ya que no estaba en la agenda del bloque de poder permitir un proceso redistributivo, sino sostener la situación 2002-2008 asentada sobre los bajos salarios en dólares. Allí se verificó un cambio significativo en la dinámica precedente, ya que en un contexto de "amesetamiento" del producto, el CRS y los usos productivos del EE pasaron a ser las variables más expansivas, mientras los destinos improductivos fueron reduciendo su participación al calor del nuevo manejo económico. No obstante, fueron más bien las transferencias estatales las que posibilitaron un aumento del CRS, por encima del crecimiento de los salarios y jubilaciones (que en el tramo 2011-2015 se estancaron, en niveles levemente superiores a los de principios de la convertibilidad), en tanto que la IP creció con aportes decisivos del sector público. Los usos improductivos se redujeron en volumen, pero la fuga de capitales continuó condicionando las cuentas externas. Todo ello en el marco de un escenario de alta inflación que ponía límites a las mejoras distributivas y un cuadro de restricción externa que condicionaba el equilibrio macroeconómico del modelo. En el escenario descrito, las mejoras en el CRS del período 2009-2015, de carácter igualmente significativo, se "amesetaron" (medidas en dólares constantes per cápita) desde 2012, en tanto que los usos producti- 
vos del EE si bien se expandieron, no lograron alcanzar el promedio del mejor período de la convertibilidad (19.7\% vs. $20.4 \%)$.

Una de las principales reflexiones que se desprenden del anterior cuadro es que los aumentos en la inversión productiva verificados en el período "populista" (2009-2015) no resultarían suficientes, a la postre, para sostener las mejoras distributivas allí observadas, lo que generó dificultades macroeconómicas hacia el último período del segundo ciclo de gobiernos kirchneristas (restricción externa) y un consecuente límite estructural para los incrementos salariales y jubi- latorios. En otras palabras, sin cambios estructurales en la matriz productiva que permitan transformar las fuentes de generación del EE, resulta difícil modificar sus mecanismos de apropiación y distribución para lograr mayores niveles de equidad a medio y largo plazo.

\section{AGRADECIMIENTOS}

El trabajo se inscribe en el PICT 33062016 de la ANPCyT. El autor cuenta con una beca doctoral del CONICET. Se agradecen los comentarios de los evaludores anónimos, así como los de Eduardo Basualdo, eximiéndolos de errores y omisiones. 


\section{REFERENCIAS}

Abeles, M. (1999). El proceso de privatizaciones en la Argentina de los noventa: ¿reforma estructural o consolidación hegemónica? Revista Época 1(1), 95-114.

Artana, D. (2001). La economía durante el plan de convertibilidad. Recuperado de https://periferiaactiva.files.wordpress.com/2011/09/artana.pdf

Azpiazu, D. \& Schorr, M. (2010). Hecho en Argentina: industria y economía, 19762007. Buenos Aires: Siglo XXI.

Baer, L. (2012). Mercado de suelo y producción de vivienda en Buenos Aires y su área metropolitana. Revista Iberoamericana de Urbanismo 8, 43-58.

Baran, P. (1975). La economía política del crecimiento. México, DF: Fondo de Cultura Económica.

Baran, P. \& Sweezy, P. (1988). El capital monopolista. México, DF: Siglo XXI editores.

Basualdo, E. (2001). Sistema político y modelo de acumulación en Argentina. Buenos Aires: Flacso-UNQ-IDEP.

Basualdo, E. (2007). Concepto de patrón o régimen de acumulación y conformación estructural de la economía. Recuperado de http://legacy.flacso.org.ar/uploaded files/Publicaciones/mep_dt01.pdf

Basualdo, E. (2010). Estudios de historia económica argentina. Desde mediados del siglo XX a la actualidad. Buenos Aires: Siglo XXI.

Basualdo, E., Manzanelli, P., Barrera, M., Wainer, A. \& Bona, L. (2015). El ciclo de endeudamiento externo y fuga de capitales. De la dictadura militar a los fondos buitre. Buenos Aires: CEFIDAR N 68 .

Bona, L. (2016a). El excedente económico y sus destinos. Una comparación entre la Argentina de la convertibilidad y la postconvertibilidad (1991-2012). Tesis de maestría. AEyT-Flacso, Argentina.

Bona, L. (2016b). Subdesarrollo y excedente económico: una conexión posible entre los aportes de Paul Baran y Celso Furtado. Cuadernos de Economía Crítica, 4(2), 95-120.

Bona, L. (2018). El costo de reproducción social en Argentina. Evolución durante los periodos de convertibilidad (1991-2001) y postconvertibilidad Sociedad y Economía No. 34, 145-166. 
CIFRA (2015, nov.). Principales resultados de pobreza e indigencia 2003-2015. Informe especial. Recuperado de centrocifra.org.ar

Cantamutto, F., Schorr, M. \& Wainer, A. (2016). El sector externo de la economía argentina durante los gobiernos del kirchnerismo (2003-2015). Realidad Económica, (304), 41-73.

Coremberg, A. (2009). Midiendo las fuentes del crecimiento en una economía inestable: Argentina. Productividad y factores productivos por sector de actividad económica y por tipo de activo. Serie estudios y perspectivas ECLAC. Buenos Aires: CEPAL.

Curia, E. (2014). El quiebre del modelo macroeconómico de desarrollo (2003-2007) y la incertidumbre hacia el futuro. La sombra del "péndulo argentino". Buenos Aires: Dunken.

Damill, M. \& Frenkel, R. (2015). La economía bajo los Kirchner: una historia de dos lustros. En C. Gervasoni \& E. Peruzzotti (eds.) ¿Década ganada? Evaluando el legado del kirchnerismo. Buenos Aires: Debate.

Danielson, A. (1990). The Concept of Surplus and the Underdeveloped Countries: Critique and Suggestions. Review of Radical Political Economics, 22(2-3), 214-230. https://doi.org/10.1177/048661349002200211

Ferrer, A. (2008). Historia económica argentina, desde sus orígenes a la actualidad. Buenos Aires: Fondo de Cultura Económica.

Fundación de Investigaciones Económicas Latinoamericanas -FIEL-. (1999). La distribución del ingreso en la Argentina. Buenos Aires: FIEL.

Furtado, C. (1978). Prefacio a una nueva economía politica. Madrid: Siglo XXI.

Gaggero, J. \& Rossignolo, D. (2012). Impacto del presupuesto sobre la equidad II. Documento de Trabajo de CEFID-AR 46.

Gaggero, J., Rúa, M. \& Gaggero, A. (2013) Fuga de capitales III. Argentina (20022012). Documento de Trabajo de CEFID-AR 52.

Guillén, A. (2007). La teoría latinoamericana del desarrollo. Reflexiones para una estrategia alternativa frente al neoliberalismo. En G. Vidal \& A. Guillén (comp.), Repensar la teoría del desarrollo en un contexto de globalización. Homenaje a Celso Furtado. Buenos Aires: CLACSO.

Harvey, D. (2005). Breve historia del neoliberalismo. Madrid: Akal. 
Instituto de Estadística y Registro de la Industria de la Construcción -IERIC- (2005). Situación actual y evolución reciente del sector de la construcción. Recuperado de www.ieric.org.ar.

Instituto Nacional de Estadísticas y Censos -INDEC-. (2017). Estadísticas del comercio exterior, términos de intercambio. Recuperado de www. indec.gov.ar

Katz, C. (2016). Neoliberalismo, neodesarrollismo, socialismo. Buenos Aires: Batalla de Ideas.

Keifman, S. (2005). Requerimientos de inversión para una estrategia de desarrollo con equidad. Recuperado de http://www.econ.uba.ar/planfenix/docnews/ inversion/keifman.pdf.

Lippit, V. (1985). The Concept of the Surplus in Economic Development. Review of Radical Political Economics 17(1-2), 1-19. https://doi. org/10.1177/048661348501700101

López, E. (2016). Los años post-neoliberales. De la crisis a la consolidación de un nuevo modo de desarrollo en Argentina. Buenos Aires: Miño y Dávila.

Marx, C. (1994). El Capital, Volumen I. Buenos Aires: Fondo de Cultura Económica.

Portelli, H. (2011). Gramsci y el bloque histórico. Buenos Aires: Siglo XXI.

Poulantzas, N. (1979). Poder político y clases sociales en el Estado capitalista. México, DF: Siglo XXI.

Prebisch, R. (1981). Capitalismo periférico. Crisis y transformación. Buenos Aires: Fondo de Cultura Económica.

Pucciarelli, A. (Coord.) (2011). Los años de Menem. La construcción del orden neoliberal. Buenos Aires: Siglo XXI.

Ricardo, D. (2007). Principios de economía politica y tributación. Buenos Aires: Claridad.

Santarcángelo, J. \& Schorr, M. (2001). Dinámica laboral en la Argentina durante los años noventa: desocupación, precarización de las condiciones de trabajo y creciente inequidad distributiva. En $V$ Congreso Nacional de Estudios del Trabajo, ASET.

Santarcángelo, J. \& Borroni, C. (2012). El concepto de excedente en la teoría marxista: debates, rupturas y perspectivas. Cuadernos de Economía, 31(56), 1-20. 
Santiere, J., Sabaini, J. \& Rossignolo, D. (2000). Impacto de los impuestos sobre la distribución del ingreso en la Argentina en 1997. Estudio preparado para la Secretaría Buenos Aires de Programación Económica y Regional en el marco del Proyecto 3958 AR-FOSIP. Buenos Aires: Banco Mundial.

Sbattella, J. (2001). El excedente económico en la República Argentina. Revista Realidad Económica, 181, 75-90.

Sbattella, J., Chena, P.; Palmieri, P. y Bona, L. (2012). Origen, apropiación y destino del excedente económico en la Argentina de la postconvertibilidad. Buenos Aires: Colihue.

Smith, A. (2010). Investigación sobre la naturaleza y causas de la riqueza de las naciones. Buenos Aires: Fondo de Cultura Económica.

Sociedad de Economía Crítica (2014). Cuadernos de Economía Crítica 1.

Somel, C. (2003). Estimating the Surplus in the Periphery: An Application to Turkey. Cambridge Journal of Economics, 27, 919-933. https://doi.org/10.1093/ cje/27.6.919

Svampa, M. (2013). La década kirchnerista: populismo, clases medias y revolución pasiva. LasaForum, 44(4), 14-17.

Varesi, G. (2014). La Argentina del kirchnerismo: notas sobre hegemonía, acumulación e integración regional. En VII Jornadas de Sociología de la $U N L P$. Departamento de Sociología de la Facultad de Humanidades y Ciencias de la Educación, La Plata.

Yeldan, E. (1995). Surplus Creation and Extraction under Structural Adjustment: Turkey, 1980-1992. Review of Radical Political Economics 27(2), 38-72. https://doi.org/10.1177/048661349502700202 


\section{ANEXO}

Evolución del costo de reproducción social (CRS) y de sus componentes en Argentina. Millones de dólares constantes de 1991. Años 1991-2015

\begin{tabular}{|c|c|c|c|c|c|c|c|c|}
\hline Año & $\begin{array}{c}\text { CRS } \\
\text { salarial }\end{array}$ & $\begin{array}{c}\text { CRS } \\
\text { jubilatorio }\end{array}$ & $\begin{array}{c}\text { Educación } \\
\text { básica }\end{array}$ & Salud & Subsidios & $\begin{array}{c}\text { Presión } \\
\text { tribut. }\end{array}$ & $\begin{array}{l}\text { CRS } \\
\text { total }\end{array}$ & $\begin{array}{l}\text { CRSI } \\
\text { PBI }\end{array}$ \\
\hline 1991 & 66.983 & 5.514 & 4.394 & 7.557 & - & \multirow{11}{*}{$29,59 \%$} & 62.996 & $36,2 \%$ \\
\hline 1992 & 79.199 & 5.433 & 5.203 & 9.165 & - & & 73.957 & $36,3 \%$ \\
\hline 1993 & 90.812 & 5.252 & 6.091 & 10.335 & - & & 84.065 & $37,7 \%$ \\
\hline 1994 & 93.123 & 5.231 & 6.555 & 11.499 & - & & 87.306 & $36,9 \%$ \\
\hline 1995 & 85.653 & 5.179 & 6.445 & 11.364 & - & & 81.763 & $35,5 \%$ \\
\hline 1996 & 80.855 & 5.019 & 6.310 & 10.892 & - & & 77.666 & $32,9 \%$ \\
\hline 1997 & 83.975 & 4.908 & 7.059 & 11.241 & - & & 80.881 & $32,6 \%$ \\
\hline 1998 & 87.318 & 4.792 & 7.103 & 11.471 & - & & 83.429 & $33,4 \%$ \\
\hline 1999 & 84.408 & 4.760 & 7.462 & 11.867 & - & & 82.112 & $35,4 \%$ \\
\hline 2000 & 80.879 & 4.212 & 7.438 & 11.437 & - & & 78.788 & $35,1 \%$ \\
\hline 2001 & 77.015 & 4.186 & 7.220 & 10.657 & - & & 75.050 & $36,3 \%$ \\
\hline 2002 & 22.847 & 1.745 & 2.265 & 3.511 & - & \multirow{14}{*}{$32,49 \%$} & 22.379 & $28,8 \%$ \\
\hline 2003 & 24.788 & 1.998 & 2.489 & 4.080 & - & & 24.651 & $26,1 \%$ \\
\hline 2004 & 36.412 & 2.501 & 3.030 & 4.714 & 95 & & 34.109 & $28,7 \%$ \\
\hline 2005 & 43.089 & 3.136 & 3.975 & 5.687 & 290 & & 41.158 & $29,6 \%$ \\
\hline 2006 & 50.442 & 3.919 & 4.827 & 6.510 & 538 & & 48.573 & $30,8 \%$ \\
\hline 2007 & 59.793 & 6.498 & 6.056 & 8.195 & 1.305 & & 60.310 & $31,9 \%$ \\
\hline 2008 & 72.745 & 7.635 & 7.765 & 10.640 & 2.252 & & 74.921 & $32,6 \%$ \\
\hline 2009 & 76.426 & 7.858 & 8.089 & 12.463 & 2.232 & & 79.685 & $37,5 \%$ \\
\hline 2010 & 89.710 & 9.223 & 9.263 & 15.124 & 2.853 & & 94.030 & $35,4 \%$ \\
\hline 2011 & 109.529 & 11.575 & 12.129 & 18.725 & 5.328 & & 117.940 & $36,9 \%$ \\
\hline 2012 & 122.928 & 14.042 & 13.021 & 21.616 & 5.447 & & 132.551 & $38,5 \%$ \\
\hline 2013 & 128.921 & 15.048 & 14.031 & 23.086 & 5.450 & & 139.761 & $39,1 \%$ \\
\hline 2014 & 110.305 & 12.986 & 12.492 & 21.184 & 5.559 & & 122.469 & $37,7 \%$ \\
\hline 2015 & 134.009 & 17.010 & 16.104 & 26.832 & 5.776 & & 150.666 & $39,9 \%$ \\
\hline
\end{tabular}

Fuente: elaboración propia con base en Ministerio de Economía y Finanzas Públicas, INDEC, Asociación Argentina de Presupuesto y Finanzas Públicas (ASAP), Ministerio de Trabajo, Empleo y Seguridad Social y US Bureau of Labor Statistics. 